\title{
MODEL SISTEM KERJASAMA DESTILASI LIMBAH CARVING DAN BAHAN LOW GRADE GAHARU MENJADI MINYAK GAHARU BERSTANDAR MARKET GUNA MENINGKATKAN NILAI TAMBAH
}

\author{
Hidayat Asta" ${ }^{\# 1}$ Erwin $^{* 2}$ \\ ${ }^{* 1}$ Program Studi Agroindustri Pangan Politeknik Negeri Sambas \\ ${ }^{*}$ Program Studi Teknik Mesin Politeknik Negeri Sambas \\ ${ }^{* 1}$ hidayatasta@rocketmail.com
}

\begin{abstract}
ABSTRAK
Gaharu memiliki prospek kedepan yang sangat baik, hal ini dilihat melalui permintaan pasar yang terus meningkat dengan harga jual yang tinggi. Bahan baku low grade memiliki harga yang rendah tetapi memiliki komponen kimia berharga tinggi sehingga sangat potensial untuk dilakukan diversifikasi produk melalui proses destilasi. Permasalahan ditingkat hunter gaharu, para hunter tidak mengambil gaharu low grade padahal dari satu pohon yang ditebang 60-80\% adalah kriteria low grade, sedangkan $20-40 \%$ baru terdapat midle-high grade. Permasalahan ditingkat praktisi adalah hasil panen yang diperoleh rata-rata gaharu low grade, tetapi mereka tidak memahami dengan baik tentang teknologi destilasi. Permasalahan ditingkat pengusaha destilasi adalah stok bahan baku yang belum stabil karena belum mempunyai jalur pemasok bahan baku yang luas. Dengan demikian, perlu dibangun pola kerjasama antara pengusaha home industri, hunter dan praktisi. Destilasi melalui metode vacum dengan tekanan 2-4 BAR, selama 16 jam menhasilkan rendemen minyak gaharu 0,03\%-0,05\% bahan low grade dan 0,07-0,10\% limbah carving. Guna menghasilkan minyak gaharu murni dengan standart market timur tengah perlu proses purifikasi tahap I dan II serta aging treatment.
\end{abstract}

Keywords - gaharu, sistem kerjasama, destilasi.

\section{PENDAHULUAN}

Gaharu memiliki prospek kedepan yang sangat baik, hal ini dilihat melalui permintaan pasar yang terus meningkat dengan harga jual yang tinggi, harga gubal dan Minyak gaharu dipasaran nasional yaitu IDR. 50.000 $\mathrm{kg}^{-1}-200.000 .000 \mathrm{~kg}^{-1}$, sedangkan minyak gaharu IDR 150.000.000 kg-1 (Data primer, 2014). Pembeli gaharu baik dalam maupun luar negeri menyukai gubal gaharu Kalbar setelah Malinau Kaltara (Data primer, 2014). Kalimantan merupakan salah satu Provinsi penyuplai gubal terbaik di Indonesia karena kwalitas gaharu Kalimantan mirip dengan gaharu kamboja yang sangat disukai oleh konsumen Saudi Arabia (Afifi, 2005).

Sistem produksi gaharu sebelumnya sepenuhnya bergantung pada tegakan liar pohon gaharu di alam, saat ini sistem produksi dapat mengoptimalkan teknologi budidaya gaharu yang telah dilakukan, dalam proses tersebut terdapat beberapa klasifikasi permasalahan utama, yaitu permasalahan pada hunter gaharu, saat eksploitasi kawasan hutan para hunter tidak mengambil gaharu low grade; bahan untuk destilasi (BUD) padahal dari satu pohon yang ditebang 60-80\% adalah kriteria low grade, sedangkan 20-40\% baru terdapat midle-high grade.

Bahan baku low grade (BUD) memiliki harga yang rendah tetapi memiliki komponen kimia berharga tinggi sehingga sangat potensial untuk dilakukan diversifikasi produk melalui proses destilasi (penyulingan). Adapun kegiatan diversifikasi produk yang telah dilakukan oleh masyarakat adalah penyulingan (Suwardi dan Edriana, 2005).

Permasalahan praktisi gaharu (petani dan pengusaha perkebunan gaharu) adalah hasil panen yang diperoleh adalah rata-rata gaharu low grade (BUD), akan tetapi mereka tidak memahami dengan baik tentang teknologi destilasi. Permasalahan ditingkat pengusaha destilasi gaharu adalah stok bahan baku yang belum stabil karena belum mempunyai jalur pemasok bahan baku yang luas. Dengan demikian, perlu dibangun pola kerjasama antara pengusaha home industri, hunter dan praktisi. 


\section{TARGET DAN LUARAN}

a. Adanya hubungan pola kerjasama dengan sistem bagi hasil (50:50) antara home industri, hunter dan praktisi dalam produksi minyak gaharu standar market

b. Mitra memahami tentang tujuan usaha budidaya gaharu, pengelolaan dan pengolahan minyak gaharu pada skala home industri.

c. Bagi pelaku usaha gaharu, lanjutan kedepannya akan menjadi model jalur sistem produksi yang potensial dalam pengolahan minyak gaharu

d. Produk yang dihasilkan berdasarkan standar market yaitu minyak gaharu pure $100 \%$, warna hitam, kental, aroma keras dan dapat bertahan hingga 12 jam.

\section{METODE PELAKSANAAN}

Proses pengolahan Minyak gaharu dilaksanakan di home industri Jl, Adisucipto Gg: Keluarga No 188F Pontianak-Kalimantan Barat-Indonesia. Dimulai April 2017November 2017.

\section{Prosedur Pelaksanaan}

Mekanisme dalam prosesing produksi minyak gaharu adalah sebagai berikut:

a. Observasi dan uji pendaluan kriteria bahan baku ideal untuk diproses menjadi minyak gaharu.

1) Berdasarkan uji organoleptik bahan baku bahwa bahan baku tersebut memiliki kandungan resin yang bervariasi dan aroma lembut - keras.

2) Spesifikasi uji organoleptik adalah hubungan kadar resin dan kualitas gaharu, hubungan komposisi kimia dengan kualitas gaharu (Pasaribu, et al., 2015).

3) Rendemen resin gaharu sangat dipengaruhi oleh kualitas gaharu. Keduanya memiliki hubungan linear di mana rendemen resin semakin meningkat sejalan dengan peningkatan kualitas gaharu (Pasaribu, et al., 2015)

4) Observasi alat destilasi, teknisi dan hasil minyak. Alat destilasi; Vacum Agarwood Destilator (VAD), kap. alat $10 \mathrm{~kg} / \mathrm{unit}$, material SS $2 \mathrm{~mm}$, minyak sesuai standar market; pure 100\%, warna hitam, cair - kental, aroma sedangkeras, bertahan hingga 12 jam setelah pemakaian. b. Kordinasi dan finalisasi sistem pembagian hasil antara hunter, praktisi (petani) dan pengusaha home industri adalah sebagai berikut:

1) Adanya hubungan pola kerjasama antara pengusaha home industri, hunter, dan praktisi dalam produksi minyak gaharu dengan standar market (Gambar 1.1)

2) Apabila terjadi proses produksi minyak gaharu maka kedua belah pihak akan mendapatkan profit $50 \%$ (hunter/praktisi [petani]) : 50\% (home industri) setelah dikurang biaya produksi.

3) Profit akan diperoleh berdasarkan sumber kepemilikan bahan baku.

c. Keseluruhan biaya produksi akan dibiaya oleh Tim Pelaksana IbM. Total biaya produksi akan diperoleh kembali setelah penjualan hasil dan akan dilanjutkan kembali untuk pembiayaan proses berikut baik dengan mitra sebelumnya maupun dengan mitra umum lainnya.

d. Koordinasi dan finalisasi Standart Operasional Prosedur (SOP) proses produksi minyak gaharu (Gambar 1.2).

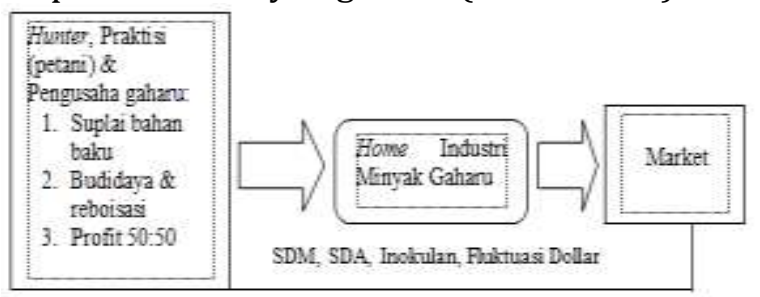

Gambar 1.1. Model Sistem Kerjasama Produksi Minyak Gaharu

e. Partisipasi mitra dalam pelaksanaan program adalah sebagai berikut:

1) Mitra berkewajiban mempersiapkan bahan bahan baku gaharu siap proses, mitra akan diberikan panduan tentang persiapan bahan baku.

2) Perwakilan mitra akan dilibatkan dalam kontrol pengawasan selama proses produksi minyak gaharu hal ini dilakukan untuk transparansi.

f. Jalur market minyak gaharu dilakukan langsung dengan buyer tetap dan tidak tetap (On-line dan Of-line) 


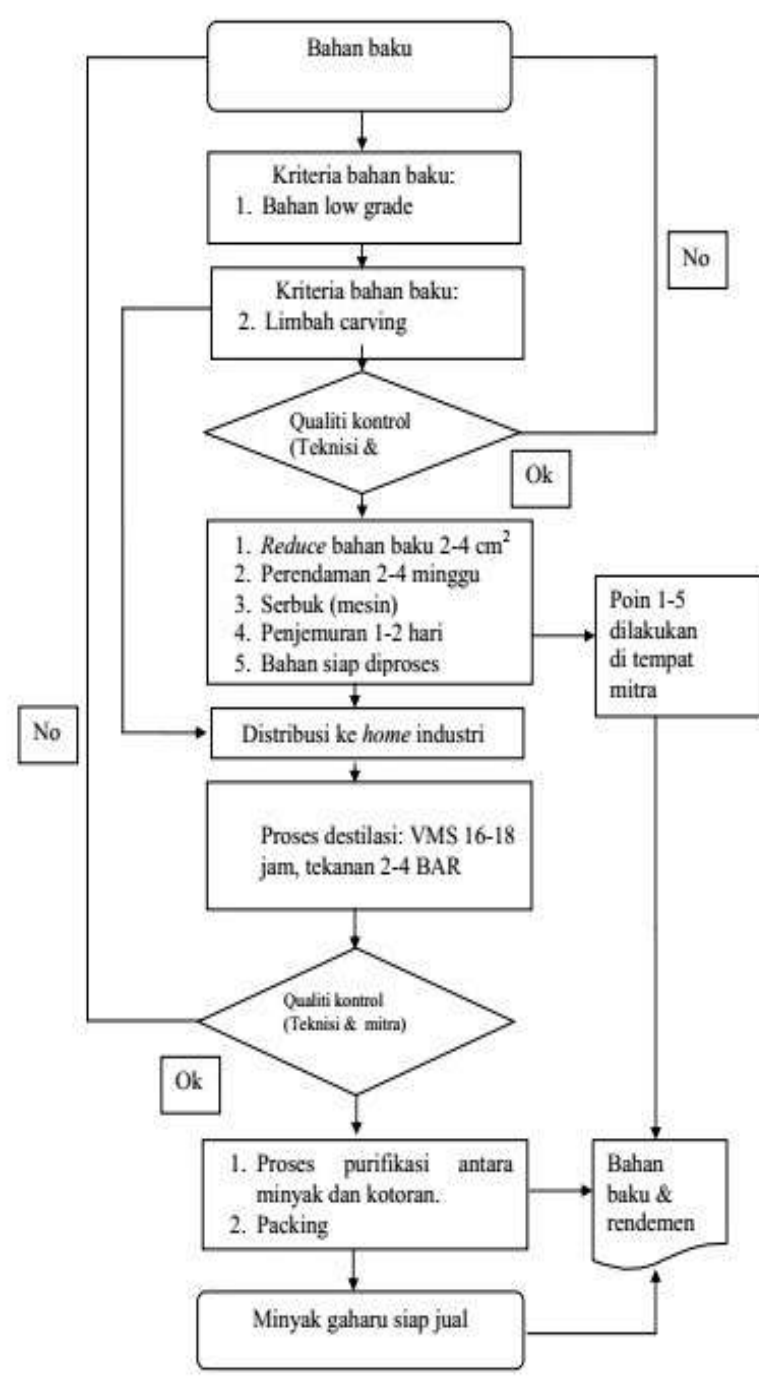

Gambar 1.2. SOP Proses Produksi Minyak Gaharu

\section{Evaluasi pelaksanaan dan keberlanjutan program IbM.}

Evaluasi perlu dilakukan dengan melihat kendala pada saat dimulai proses produksi, adapun inti evaluasi tersebut adalah:

a. Evaluasi kriteria bahan baku ideal dan stok bahan baku

b. Evaluasi distribusi bahan baku ke tempat home industri minyak gaharu

c. Evaluasi proses produksi minyak gaharu

d. Evaluasi sistem market minyak gaharu

\section{HASIL DAN PEMBAHASAN}

\section{Sosialisasi dan Kordinasi Pelaksanaan.}

a. Sumber bahan baku; persiapan bahan baku dan tata cara persiapan, tim pelaksana memberikan jobsheet persiapan bahan baku agar diperoleh bahan baku dengan kwalitas yang baik.

b. Tentang persiapan alat dan mesin destilasi bagi mitra home industri. c. Pembahasan mekanisme bagi hasil dengan kesepakatan pembagian 50:50 setelah dikurangi khusus biaya produksi; tenaga kerja dan belanja bahan isi LPG. Hal ini sesuai dengan pola awal yang ditawarkan oleh Tim pelaksana.

d. Gambaran tentang trading dan market minyak gaharu dan akan memungkinkan dikelola oleh mitra dan tim pelaksana sebagai pola bimbingan dan kerjasama lanjutan guna memperoleh nilai jual yang standart.

\section{Persiapan Bahan Baku dan Distribusi Bahan Baku.}

a. Bahan baku tahap I yang terkumpul dari mitra adalah bahan low grade dengan spesifik sebagai berikut:

1) Berdasarkan hasil sortir bahwa bahan baku low grade tergolong pohon gagal panen dan sehingga kandungan minyak gaharu sangat rendah,

2) Bahan limbah carving masuk pada katagori abuk low grade karena bukan abuk hasil carving finishing akan tetapi abuk carving bagian gubal.

3) Bahan yang diperoleh masih perlu dilakukan sortir ulang karena masih banyak kayu putih yang ikut tercampur didalam tumpukan bahan baku.

b. Proses distribusi bahan baku diperlukan dokumen surat keterangan asal usul kayu

c. Proses selanjutnya adalah perlakuan perendaman dalam bak dan siap proses produksi minyak gaharu.

d. Tujuan perendaman adalah memisahkan kelenjar minyak dari sel parenkim agar selsel parenkim menjadi lunak dan menambah aroma, uniknya aroma minyak yang pada awalnya direndam 1 bulan lalu disuling timbul aroma tidak sedap, namun setelah disimpan beberapa lama aromanya akan berubah kembali ke asalnya lebih tinggi dan kuat serta melekat erat dikulit (Ramlan, 2008).

e. Berdasarkan hasil minyak yang diperoleh, perendaman menggunakan air selama 5 hari dengan kondisi penyulingan suhu $100^{\circ} \mathrm{C}$ dan tekanan $2,8 \mathrm{kgf} / \mathrm{cm}^{2}$, menghasilkan minyak gaharu lebih banyak dengan rendemen 0,125\%, sedangkan tanpa perendaman menghasilkan 
rendemen minyak sebesar $0,100 \%$ dengan kondisi penyulingan yang sama (Adiningsih, 2011).

\section{Persiapan Alat dan Mesin Destilasi.}

a. Pemeriksaan dinamo mesin chiper, valve $3 / 4$ dan kebocoran tabung destilator.

b. Alat dan mesin yang perlu dilengkapi adalah bak perendaman, mesin air, elbow dan arco sorong.

c. Pengaturan tata letak alat produksi dan jadwal produksi.

\section{Produksi Minyak Gaharu.}

a. Destilasi melalui metode vacum dengan tekanan 2-4 BAR, selama 16 jam menhasilkan rendemen minyak gaharu 0,03\%-0,05\% (bahan low grade) dan 0,07$0,10 \%$ (limbah carving).

b. Rendemen minyak sangat dipengaruhi oleh tingkat kandungan resin dan lama waktu proses pemanenan bahan baku.

c. Proses produksi minyak gaharu mengikuti protokol destilasi (Gb. 3.1).

\section{Purifikasi dan Packing Minyak Gaharu Standart Market.}

a. Purifikasi dilakukan dengan metode sederhana yaitu proses dekantasi dan corong pisah, larutan diendapan kemudian dipisahkan dengan droping pipet atau pengaturan kran pada corong pisah.

b. Faktor yang mempengaruhi purifikasi adalah keterampilan dalam pengambilan minyak dengan droping pipet manual.

c. Keseluruhan bahan baku low grade dan limbah carving menghasilkan minyak murni standart market timur tengah.

d. Proses selanjutnya yang dapat diterapkan adalah proses aging treatment untuk memperkuat aroma top note, suhu $30-35^{\circ} \mathrm{C}$ selama 72 jam.

e. Packing menggunkan botol kecil atau tola vol. $12 \mathrm{ml}$ dan dikemas dengan box kayu.

\section{Monitoring dan Evaluasi Pelaksanaan Program IbM.}

a. Teknik sortir bahan baku oleh mitra belum sepenuhnya terampil sehingga kedepan diperlukan bimbingan teknis agar kwalitas minyak yang dihasilkan baik.

b. Berdasarkan hasil yang diperoleh, rendemen minyak gaharu bahan low grade tergolong rendah yaitu sekitar 0,03\%$0,05 \%$, akan tetapi dari hasil produksi tersebut dapat memberikan pendapatan sebesar $150.000-500.000$ / $10 \mathrm{~kg}$ bahan baku.

c. Faktor yang harus diperhatikan dalam produksi minyak gaharu dari bahan low grade adalah viscositas minyak dan aroma minyak gaharu sehingga perlakuan tekanan BAR dalam produksi tidak boleh terlalu tinggi, yaitu cukup pada tekanan 2.5 -3 BAR.

1) Sistem bertekanan memiliki kelebihan yakni pada jumlah minyaknya yang lebih banyak namun jika kurang hatihati minyaknya cendereung hitam dan gosong karena suhu dan tekanan yang tinggi (Yuliansyah dan Kholik, 2004).

\section{KESIMPULAN DAN SARAN \\ Kesimpulan}

Adapun kesimpulan dari pelaksanaan program IbM adalah sebagai berikut:

a. Rendemen minyak gaharu bahan low grade $0,03-0,05 \%$ dan limbah carving 0,07 $0,10 \%$ melalui destilasi metode vacum 16 jam tekanan 2-4 BAR

b. Menghasilkan minyak gaharu murni dengan standart market timur tengah setelah proses purifikasi tahap I dan II serta aging treatment selama 72 jam dengan suhu $30-35^{\circ} \mathrm{C}$.

c. Produk minyak gaharu murni diserahkan kepada mitra I dan mitra III, berdasarkan prinsip model sistem kerjasama produksi minyak gaharu.

d. Mitra I hunter berperan aktiv dalam suplai bahan baku ke tempat mitra III home industri minyak gaharu.

e. Terjalin pola hubungan kerjasama produksi minyak gaharu secara berkelanjutan dan kedepan akan menjadi terpadu diantara pelaku usaha.

f. Memperoleh pendapatan dari hasil pengolahan minyak gaharu, yang sebelumnya bahan baku tersebut belum memberikan manfaat.

\section{Saran}

Perlunya bimbingan teknis secara intensif terhadap mitra dalam proses persiapan bahan baku khususnya sortasi dan cara kerja resize manual. 


\section{UCAPAN TERIMA KASIH}

Direktorat Riset dan Pengabdian Masyarakat Direktorat Jenderal Penguatan Riset dan Pengembangan Kementerian Riset, Teknologi, dan Pendidikan Tinggi, P3M Politeknik Negeri Sambas dan Mitra Program IbM.

\section{DAFTAR PUSTAKA}

Adiningsih, Y., 2016. Perlakuan Perendaman Pada Proses Penyulingan Minyak Atsiri dari Gaharu Bermutu Rendah. Jurnal Riset Teknologi Industri, 5(9), pp.22-27.

Afifi, 2005. Budidaya, Teknis Inokulasi, Cara Pemanenan dan Industri Gaharu. Asgarin. pp. 3.

Pasaribu, G., T. K. Waluyo, dan G. Pari. 2015. Seri Paket Iptek Penyusunan Standar Mutu Gaharu. Pusat Penelitian dan Pengembangan Hasil Hutan Badan Penelitian, Pengembangan dan Inovasi Kementerian Lingkungan Hidup dan Kehutanan. Bogor.

Ramlan, M.F., 2008. Optimization of Agarwood Oil Extraction by using design of Experiment (DOE) method (Doctoral dissertation, UMP).

Suwardi, E. dan E. Edriana. 2005. Gaharu dan Prospek Peningkatan Nilai Tambah Melalui Penyulingan Tepat Guna. Makalah Disampaikan pada Seminar Nasional Gaharu, Bogor 1-2 Desember 2005. Badan Litbang Kehutanan, Bogor.

Yuliansyah dan A. Kholik, 2004. Pemanenan, Pengolahan dan Pemasaran Gaharu. Makalah Dalam Promosi Penembangan Gaharu di Kab. Pasir. Grogot. 